\title{
Analysis of Different Ball Point Pen Inks Using Thin Layer Chromatography and Comparison with FTIR Spectrometer
}

\author{
MANOJ D. BANSINGE, PRADIP V. TEKADE, SONAL D. BAJAJ*, \\ OM A. MAHODAYA and NAKUL A.BARWAT
}

Department of Chemistry, Jankidevi Bajaj College of Science, Jamnalal Bajaj Marg, Civil lines, Wardha-442001(MS), India.

sonu1star@gmail.com

Received 1 August 2018 / Accepted 3 September 2018

\begin{abstract}
In this study the black, blue and red ball point inks were classified into two groups using the $\mathrm{R}_{\mathrm{f}}$ values. Color tones of dyestuff bands were separated by normal phase thin layer chromatography (TLC). The classification is effective for the preliminary identification of ball point ink which is used for document forgery. Furthermore, the separated components were analyzed by means of Fourier Transform Infrared Spectroscopy (FTIR). FTIR analysis revealed that each band can be characterized and then differentiated by looking the pattern of each spectrum. The results are complementary for TLC and FTIR and these are non-destructive methods.
\end{abstract}

Keywords: Forensic analysis, Ball pen ink, TLC, FTIR spectroscopy

\section{Introduction}

Ink analysis is an important forensic procedure that can reveal useful information about questioned document. Modern inks contain many substances aiming to improve ink characteristics ${ }^{1-3}$. Obviously, the most important component is the coloring material, which comes in the form of dyes, pigments or their combination. Dyes are soluble in the liquid body of the ink, which is also known as the vehicle. On the other hand, pigments are finely ground multi-molecular granules that are insoluble in the vehicle. The vehicle, whose composition affects the flowing and drying characteristics of the ink, can consist of oils, solvents and resins. Other substances used for finely tuning the characteristics including driers, plasticizers, waxes, greases, soaps and detergents ${ }^{4}$.

The techniques regarding the analysis of inks can be divided into non-destructive and destructive approaches. The nondestructive method, however, is preferable there is a more limited range of such techniques available to the forensic examiner. Among these, the use of IR absorption and luminescence carried out in a video spectral comparator or a similar instrument is highly successful particularly for black inks. Other non-destructive techniques include Raman ${ }^{5}$ and surface-enhanced resonance Raman spectroscopy (SERRS) ${ }^{6}$, UV-Vis micro-spectrophotometry. 
Removal of a small section of the ink line followed by solvent extraction of the ink opens up more avenues of analysis. Analytical techniques such as thin layer chromatography, high performance liquid chromatography (HPLC), infrared spectroscopy (FTIR) and capillary electrophoresis have been applied to the analysis of inks ${ }^{7-15}$.

Thin layer chromatography (TLC) is widely used because it is rapid, inexpensive and horary destructive of documents. In this method, qualitative evaluation of the chromatograms is often performed using the retention factor $\left(\mathrm{R}_{\mathrm{f}}\right)$ values, but it is not accurate, especially when comparison of ink to a database of chromatograms is desired. Direct scanning of chromatograms can be performed using scanning densitometers, but unfortunately, it has low signal-to-noise ratio, due to large scanning area arranged initially as the diameter of the largest spot.

In the present paper, we have described a preliminary preparation of standard TLC library for ink, also discusses the effectiveness of TLC for identification of writing implements. We have also reported the application of pin point technique to the identification of dye TLC band by Fourier transform infrared spectroscopy (FTIR).

\section{Experimental}

Twelve ball point pens were purchased from local market the trademarks of collected samples are listed in Table 1

Table 1. List of studied different ball point pens ink

\begin{tabular}{ccc}
\hline S.No. & Name of ball point ink pens & Code \\
\hline 1 & Cello finegrip blue & cfbla \\
2 & Cello finegrip black & cg black \\
3 & Cello finegrip red & cf red \\
4 & Cello gripper blue & cg blue \\
5 & Cello gripper Black & cg black \\
6 & Cello gripper Red & cg red \\
7 & Pentek stylo Blue & pentek blue \\
8 & Pentek stylo Black & pentek black \\
9 & Pentek stylo Red & pentek red \\
10 & Reynold brite Blue & reynold blue \\
11 & Reynold brite Black & reynold black \\
12 & Reynold brite Red & reynold red \\
\hline
\end{tabular}

\section{TLC Analysis}

\section{Preparation of the sample}

Developing chamber was prepared by adding about $5 \mathrm{~mL}$ of developing solution to the chamber (Figure 1). Appropriate sections were removed from the specimen document with a pair of scissors; they were cut into a few pieces and placed in a $10 \times 75 \mathrm{~mm}$ test tube. If variations of ink on one document were suspected, different sections were separated and well labeled. The ink was extracted from the paper using 2-3 $\mathrm{mL}$ of methanol. The test tubes were heated in a water bath to increase the solubility of the ink. For removal of the ink from the pieces of the paper, hot methanol was squirt over the pieces of the paper using a Pasteur pipette. When the methanol solution is fairly dark from the ink, the ink solution was transferred from the test tubes to a small tube. 


\section{Spotting of the sample}

TLC plate was handled by the edges only, making sure to avoid touching the white silica layer. A pencil and ruler was used to draw a line about $1 \mathrm{~cm}$ from the bottom of the plate. Capillary tube was immersed into the sample tube until some of the liquid was drawn in to the capillary. The small end of the capillary tube was gently pressed at a crosshair on the TLC plate. Small spot was spotted by touching the capillary quickly to the plate and then removing it immediately. The spot was allowed to dry and spotting was repeated directly over original spot. UV-lamp was used to ensure the visualization of spot.

\section{Development of the sample}

Three different developing solvents were used for these analyses.

Developing Solvent 1: $n$-butyl alcohol: ethyl alcohol: water: acetic acid - 60: 10: 20: 0.5

Developing Solvent 2: methanol: acetone: water- 40: 40: 19.5

Developing Solvent 3: acetic acid: pyridine: methanol- 40: 40: 19.5

The position of the sample spots on the thin-layer plate and the solvent level in the chromatography jar was checked carefully. Plate was placed vertically in the developing jar with the upper edges only resting against the jar. The jar was resealed and the solvent was allowed to rise until it was about $2-3 \mathrm{~cm}$ from the top of the plate. TLC plate was removed using tweezers and immediately marked where the solvent stopped rising with a pencil. This was called the solvent front. TLC plate was allowed to dry. The spots were visualized by illumination under the UV lamp. Center of each spot was circled with a pencil and then distance traveled by each component was measured (Figure 2-7).

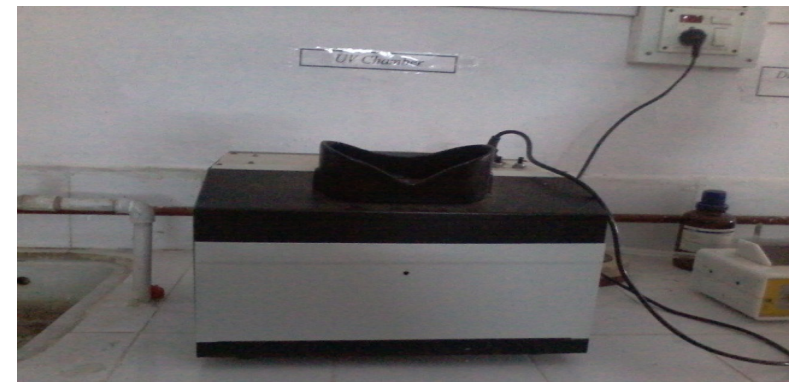

Figure 1. UV Chamber
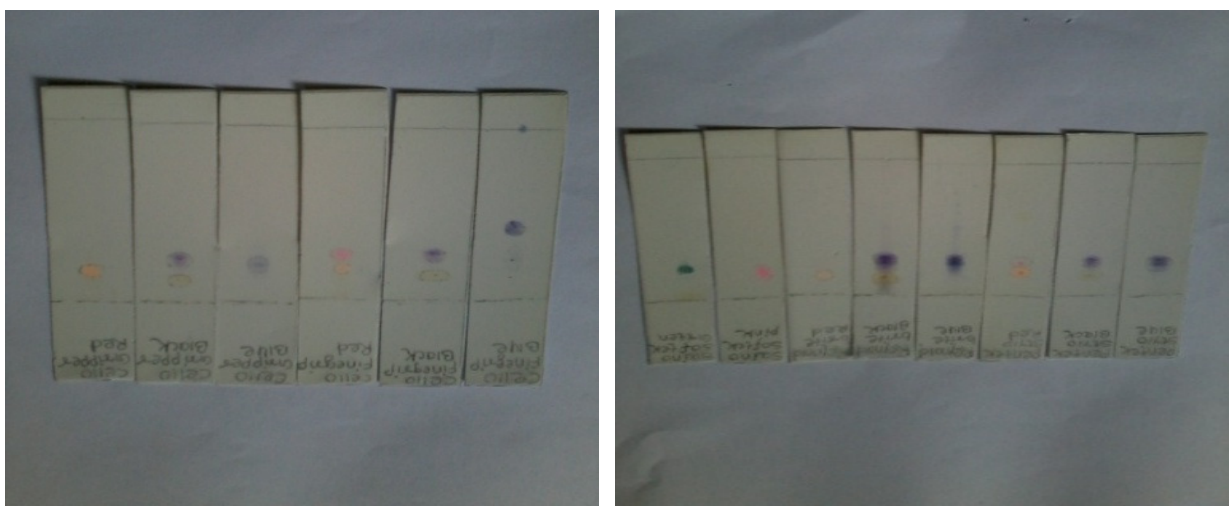

Figure 2. Spots of different inks on TLC plates in solvent 1 

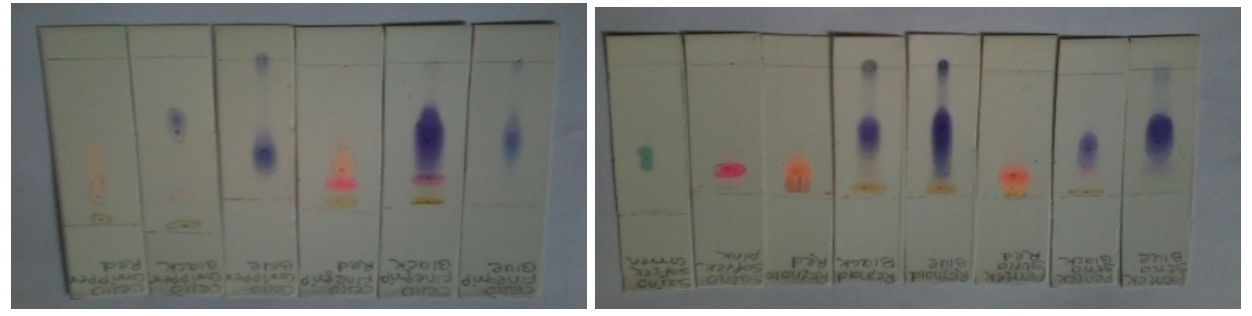

Figure 3. Spots of different inks on TLC plates in solvent 2
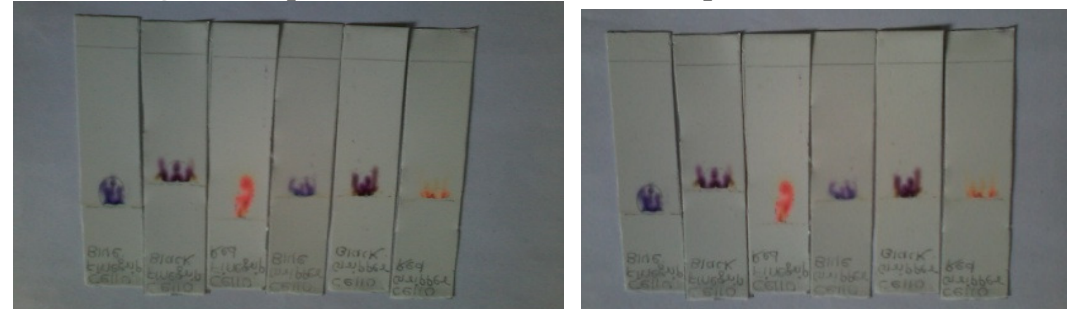

Figure 4. Spots of different inks on TLC plates in solvent 3

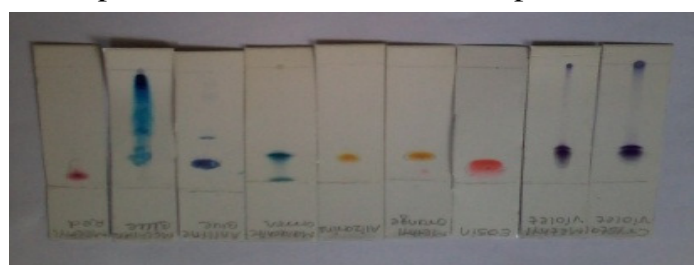

Figure 5. Spots of different standard inks on TLC plates in solvent 1

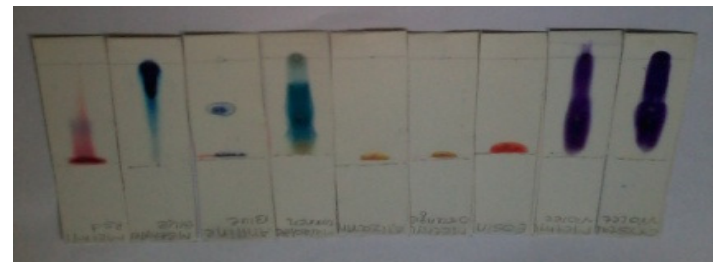

Figure 6. Spots of different standard inks on TLC plates in solvent 2

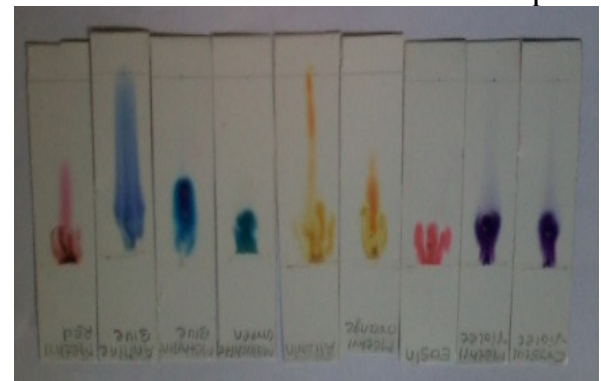

Figure 7. Spots of different standard inks on TLC plates in solvent 3

\section{FTIR spectroscopy}

FT-IR analysis was carried out on a Bruker Alfa FTIR spectrometer. A Zn-Se crystal tip ATR objective was used as micro-sampling accessory. The background spectrum was 
reacquired after every analysis to reduce variation in the spectra due to instrumental drift. Each spectrum was the result of an average of 16 scans at $4 \mathrm{~cm}^{-1}$ resolution over a spectral range of 4000 to 550 wave numbers $\left(\mathrm{cm}^{-1}\right)$.

\section{Results and Discussion}

$T L C$

$R_{f}$ value for each sample was measured and the results are shown in Table 2. Moreover, optimization study was done with some standard dyes given in Table 3

Table 2. TLC analysis for ink samples

\begin{tabular}{|c|c|c|c|c|c|c|c|}
\hline \multirow[t]{2}{*}{ S.No. } & \multirow{2}{*}{$\begin{array}{l}\text { Ink Sample } \\
\text { Code }\end{array}$} & \multicolumn{2}{|c|}{ Solvent 1} & \multicolumn{2}{|c|}{ Solvent 2} & \multicolumn{2}{|c|}{ Solvent 3} \\
\hline & & Color & $\mathrm{R}_{\mathrm{f}}$ & Color & $R_{f}$ & Color & $\mathrm{R}_{\mathrm{f}}$ \\
\hline 1 & cfbla & Violet & 0.78 & Violet & 0.53 & Violet & 0.84 \\
\hline \multirow[t]{2}{*}{2} & cg black & Violet & 0.72 & Violet & 0.53 & Violet & 0.88 \\
\hline & & Yellow & 0.84 & Pink yellow & 0.78 & & \\
\hline \multirow[t]{2}{*}{3} & cfred & Orange & 0.82 & Orange & 0.74 & Orange & 0.90 \\
\hline & & Violet & 0.77 & Pink yellow & 0.82 & & \\
\hline \multirow[t]{2}{*}{4} & cg blue & Violet & 0.75 & Violet & 0.66 & Violet & 0.89 \\
\hline & cg black & Yellow & 0.86 & Blue & 0.43 & Violet & 0.88 \\
\hline \multirow[t]{2}{*}{5} & & Orange & 0.81 & Pink & 0.77 & & \\
\hline & & & & yellow & 0.94 & & \\
\hline \multirow[t]{2}{*}{6} & cg red & Violet & 0.71 & Orange & 0.83 & Orange & 0.95 \\
\hline & & & & yellow & 0.96 & & \\
\hline \multirow[t]{2}{*}{7} & pentek blue & Blue & 0.76 & Violet & 0.55 & Violet & 0.88 \\
\hline & & Violet & 0.76 & & & & \\
\hline \multirow[t]{3}{*}{8} & pentek black & Yellow & 0.86 & Violet & 0.58 & Violet & 0.85 \\
\hline & & Orange & 0.84 & Pink & 0.81 & & \\
\hline & & & & Yellow & 0.95 & & \\
\hline \multirow[t]{2}{*}{9} & Pentek red & Pink & 0.76 & Orange & 0.8 & Orange & 0.93 \\
\hline & & Violet & 0.72 & Yellow & 0.95 & & \\
\hline \multirow[t]{2}{*}{10} & Reynold blue & Blue & 0.74 & Violet & 0.54 & Violet & 0.88 \\
\hline & & Violet & 0.73 & Yellow & 0.93 & & \\
\hline \multirow[t]{2}{*}{11} & Reynold black & Yellow & 0.86 & Violet & 0.55 & Violet & 0.88 \\
\hline & & Orange & 0.86 & Yellow & 0.93 & & \\
\hline 12 & Reynold red & Pink & 0.74 & Orange & O82 & Orange & 0.95 \\
\hline
\end{tabular}

Table 3. TLC analysis for dyes (Standards)

\begin{tabular}{cccccccc}
\hline \multirow{2}{*}{ S.No. } & \multirow{2}{*}{ Dyes } & \multicolumn{2}{c}{ Solvent 1} & \multicolumn{2}{c}{ Solvent 2} & \multicolumn{2}{c}{ Solvent 3 } \\
\cline { 3 - 8 } & & Color & $\mathrm{R}_{\mathrm{f}}$ & Color & $\mathrm{R}_{\mathrm{f}}$ & Color & $\mathrm{R}_{\mathrm{f}}$ \\
\hline 1 & Crystal Violet & Violet & 0.76 & Violet & 0.59 & Violet & 0.82 \\
2 & Methyl Violet & Violet & 0.76 & Violet & 0.60 & Violet & 0.8 \\
3 & Eosin & Orange & 0.86 & Orange & 0.87 & Orange & 0.92 \\
4 & Methyl Orange & Yellow & 0,82 & Yellow & 0.97 & Yellow & 0.88 \\
5 & Alizarin & Yellow & 0.8 & Yellow & 0.93 & Yellow & 0.86 \\
6 & Malachite Green & Green & 0.77 & Green & 0.60 & Green & 0.8 \\
7 & Aniline Blue & Blue & 0.77 & Blue & 0.48 & Blue & 0.8 \\
8 & Methylene Blue & Blue & 0.75 & Blue & 0.45 & Blue & 0.72 \\
9 & Methyl Red & Red & 0.90 & Red & 0.93 & Red & 0.93 \\
\hline
\end{tabular}




\section{Optimization study of solvents for TLC Solvent system-1}

$n$-Butyl alcohol/ethyl alcohol/distilled water/acetic acid (60:10:20:0.5): This solvent system shows better separation, still it is not so good because it does not tell about some of the component. Very little separation was observed so dyes seem to coming together.

\section{Solvent system-2}

Methanol /acetone/distilled water (40:40:19.5): This solvent system shows separation much more clear than other solvent. Moreover clear spots were appeared, the components were clearly separated.

\section{Solvent system-3}

Acetic acid/pyridine/methanol(40:40:19.5): There was some trailing. Separation was not as good as other solvent systems as dyes having trailing.

It was observed that results were affected by the selection of proper extraction solvent to remove ink from a plate. Methanol was reported solvent used with ball point pen inks. In this work, the extraction was preformed with different solvents. The obtained result reveals that immersion of paper into methanol and simple agitation could result complete extraction of inks from paper. Methanol was chosen by considering the safety of the solvent. The choice of the plate (stationary phase) and mobile phase was made regarding the nature of the sample. Many types of TLC plates were examined and found that silica gel plates provided better resolution of dye spots. Because of easy handling, alumina sheet silica gel is preferred in these studies. Many mobile phase system were investigated in this work then few mobile phase were selected and found that solvent system-2 methanol/acetone/distilled water (40:40:19.5), was effective in separating nearly all dye mixtures.

\section{FTIR Analysis}

FTIR spectrum of all 12 ink samples shown in Figure 8. The 12 ink samples can be classified into two groups according to their spectral characteristics. In the first group, there was no peak shown in the range from 2000 to $1700 \mathrm{~cm}^{-1}$, which is the characteristic frequency of carbonyl $(\mathrm{C}=\mathrm{O})$ stretching vibration. This means that there were no aliphatic acid or their esters present. The peak at 1585,1362 and $1174 \mathrm{~cm}^{-1}$ belongs to the characteristic absorption of triarylmethane dyes. The peak at $1242 \mathrm{~cm}^{-1}$ can be assigned to the vibration of aromatic ether (Ar-O) and the absorption bands at $1298,1034 \mathrm{~cm}^{-1}$ reflected the asymmetrical and symmetrical stretch vibration of aliphatic ether $(\mathrm{C}-\mathrm{O})$. Moreover, the absorption band at $912 \mathrm{~cm}^{-1}$ was caused by terminal epoxy bond. It should be noticed that most of the absorption bands in the inks spectra are complex peaks. For example, the stretch vibration of an unsaturated $\mathrm{C}-\mathrm{H}$ bond and the asymmetrical vibration of $-\mathrm{CH}_{2}$ in the epoxy resin caused the absorption band at $3062 \mathrm{~cm}^{-1}$. (In cyclic compounds, as the cyclic tension and the extent of $\mathrm{sp}^{2}$ hybrid increased, the stretch vibration of $-\mathrm{CH}_{2}$ will be shifted to high frequency). Meanwhile the absorption band at $1584 \mathrm{~cm}^{-1}$ contained the skeletal vibration of triarylmethanedye and the $\mathrm{C}=\mathrm{C}$ stretch vibration of epoxy resin (about $1581 \mathrm{~cm}^{-1}$ ). The absorption frequency at $1360 \mathrm{~cm}^{-1}$ alsocontains the symmetrical bending vibration. The analysis results shows triarylmethane dyes, the epoxy resin, and the solvents existed in the first group of inks.

In the second group, there was a strong absorption band of carbonyl $(\mathrm{C}=\mathrm{O})$ from 2000 to $1700 \mathrm{~cm}^{-1}$. According to the strong carbonyl $(\mathrm{C}=\mathrm{O})$ absorption band at $1725 \mathrm{~cm}^{-1}$ and the asymmetrical and symmetrical stretch vibration of the C-O-C bonds at 1293, 1129 and 
$1067 \mathrm{~cm}^{-1}$, the presence of ester could be confirmed. The spectrum also indicated that the main component in this kind of ink was alkylated resin. On the contrary, the absorption bands of the triarylmethane dyes were not noticeable.

It is obvious that the blue ballpoint pen ink is a mixture of dyes such as triarylmethane dyes, epoxy resin, alkylated resin and solvents, etc.
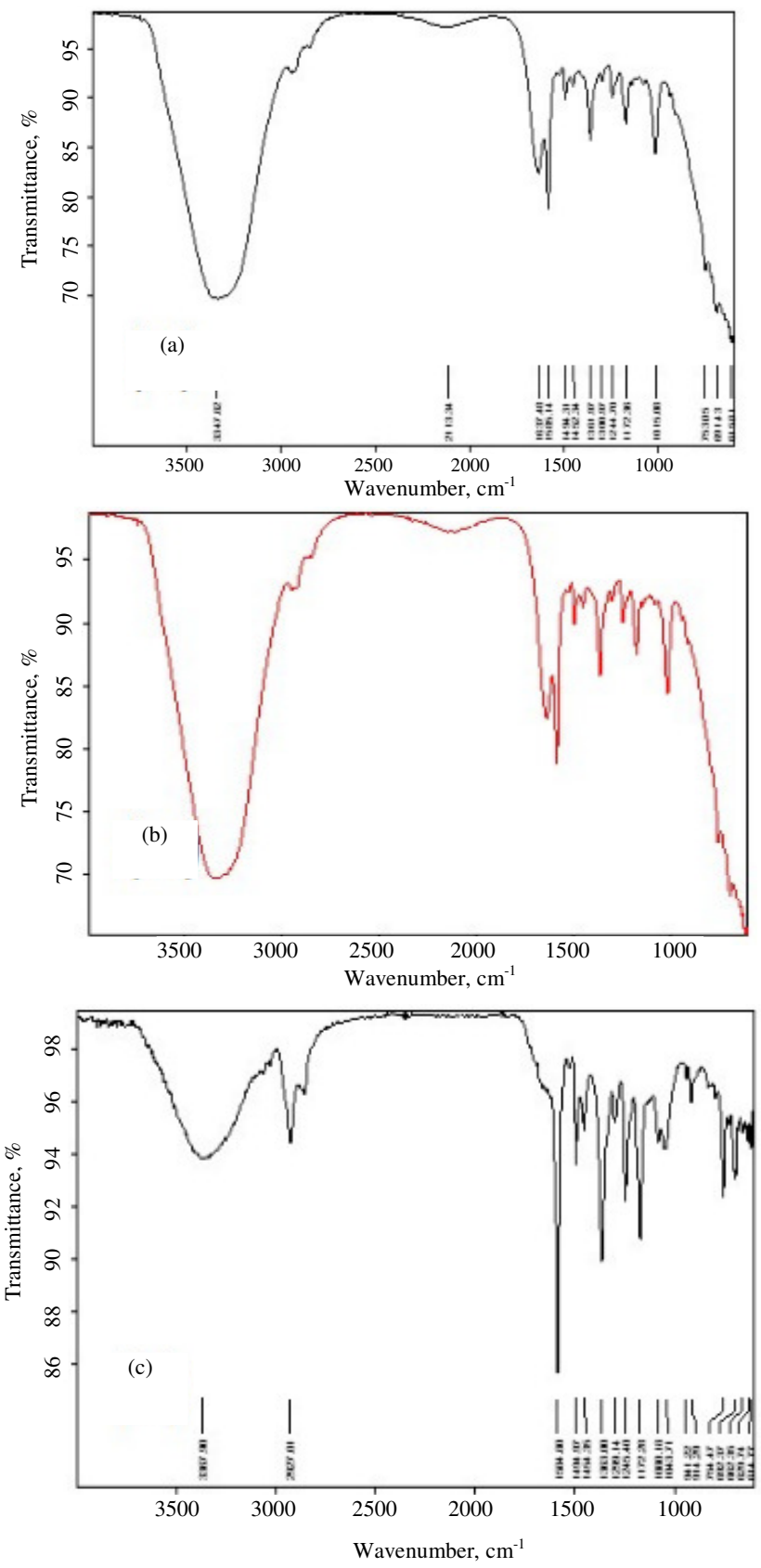

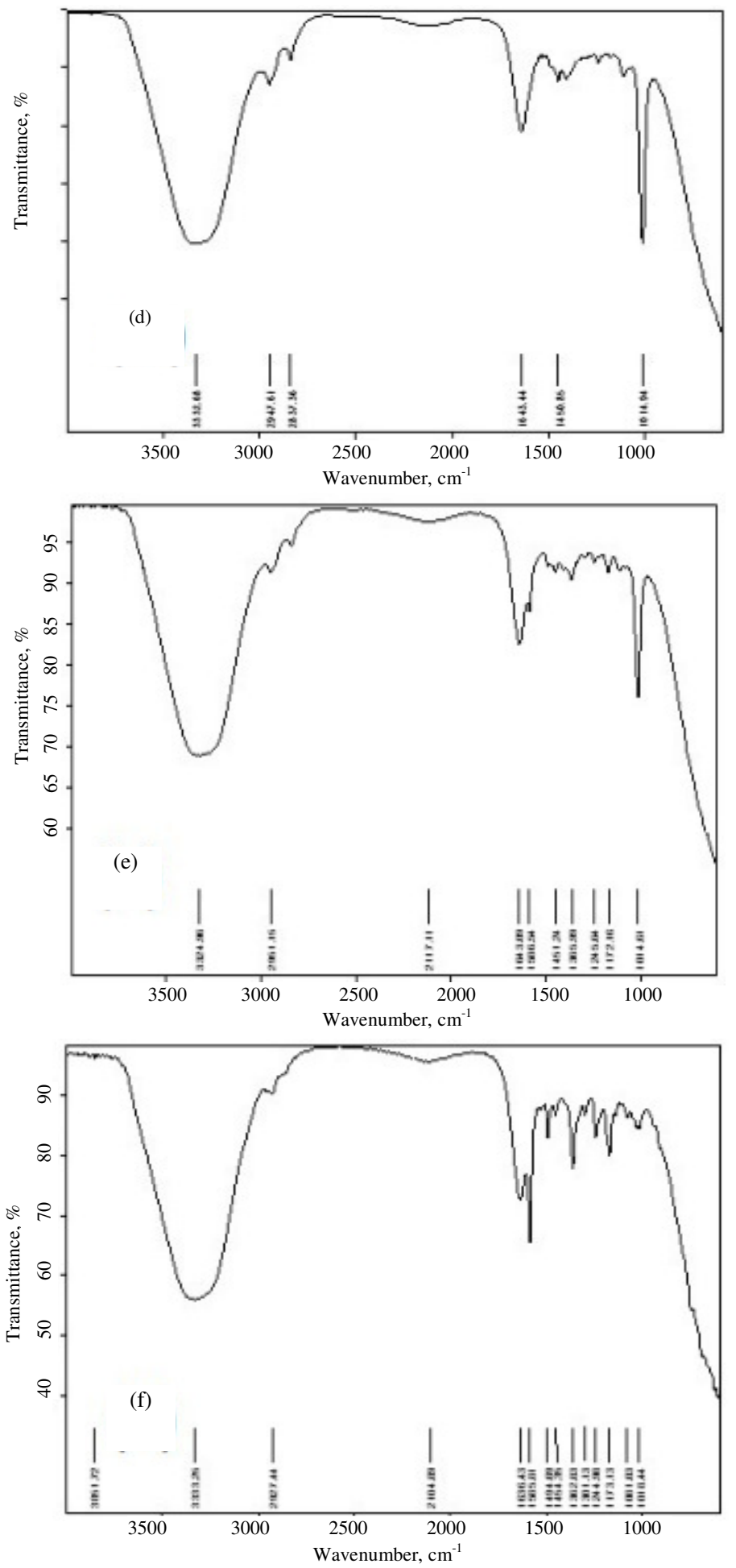

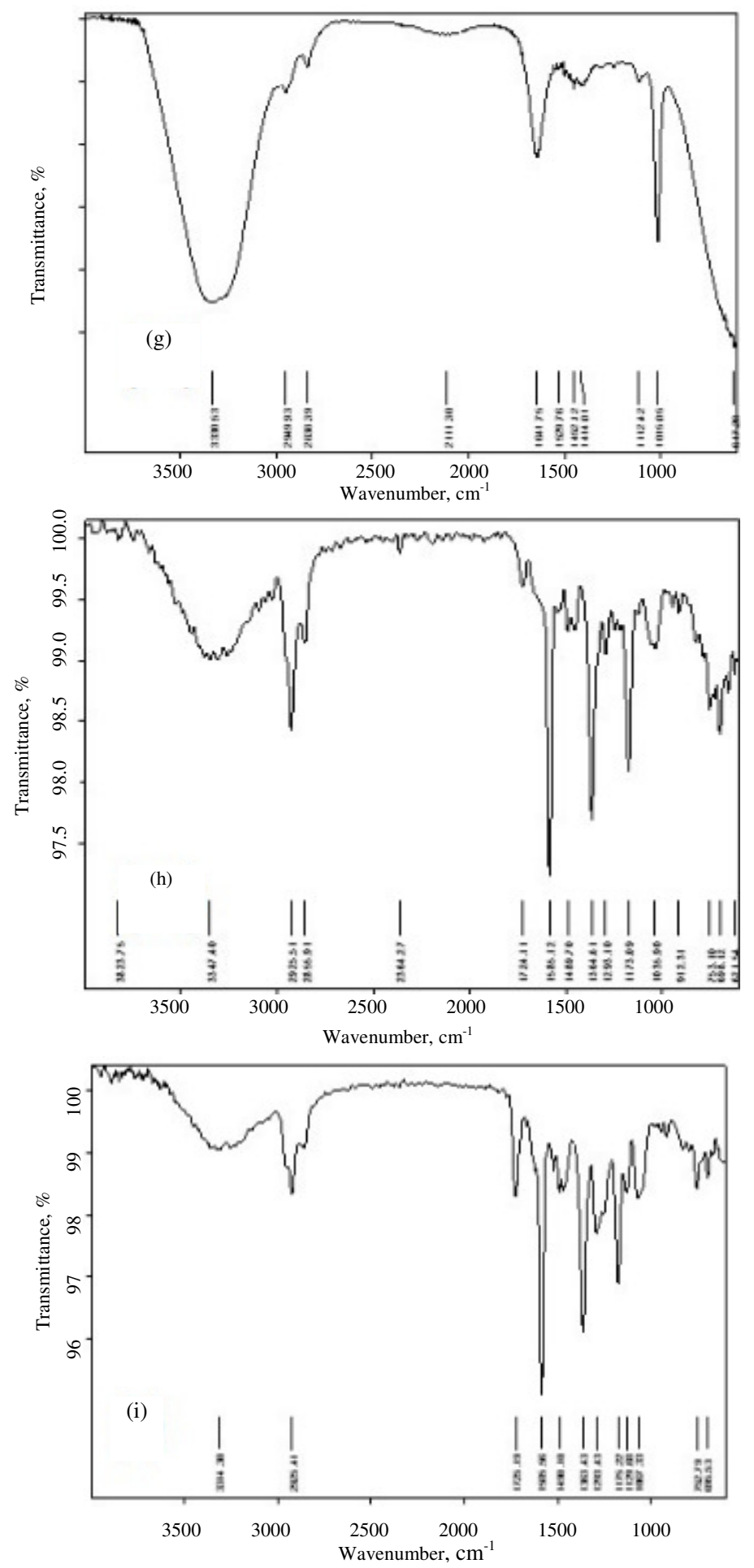

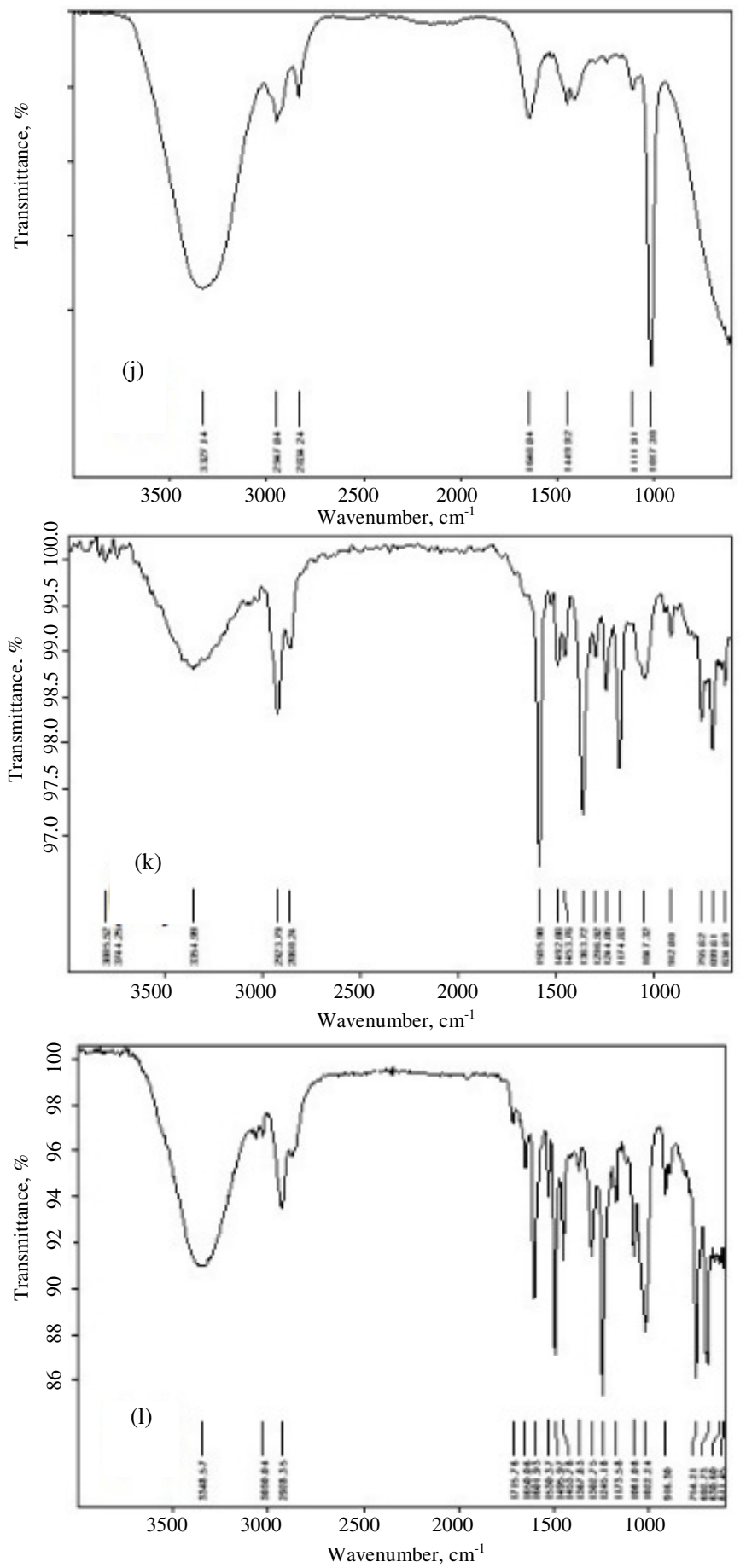

Figure 8. FTIR spectrum of (a) cfbla (b) cg black (c) cf red (d) cg blue (e) cg black (f) cg red (g) pentek blue (h) pentek black (i) pentek red (j) reynold blue (k) reynold black (l) reynold red 


\section{Conclusion}

Non-destructive physical methods such as FTIR remain important valuable tools for the examination of forgery as they do not alter the visual morphology of the document. This is very important especially in the case of documents that have historical or financial value. Current findings indicated that examiners should use extreme caution in relying on these methods as every test of them has its disadvantage or limitation but not easy to discriminate these inks since all the samples have the same formulation. Similar inks, which could not be differentiated by the previous methods, were distinguished using TLC. The results of TLC showed that blue inks 1, 4 and 7, 10 (Inks) are of one similar composition while blue inks 1, 4 and 7, 8(standard dyes) are different from each other. Black inks 2, 5, 8 and 11 are of two similar compositions. Similarly red inks 3 and 9 are of two similar compositions while red inks 6 and 12 are of one similar composition.

TLC technique, therefore still has a very important role to play in the routine examination of inks, although a great deal of research is currently under way involving the evaluation of more sophisticated and sensitive instrumentation for ink analysis.

Our results and our final conclusion suggested that TLC technique is a complementary and very useful. Although FTIR is a well-established \& non-destructive technique for the comparison of inks but not easy to discriminate these inks since all the samples have the same formulation.

\section{Acknowledgement}

Authors are thankful to all the faculty of Department of Chemistry, Jankidevi Bajaj College of Science, Wardha for the support to carry out this research work.

\section{References}

1. Vogt C, Vogt J, Becker A and Rohde E, J Chromatogr A, 1997, 781(1-2), 391-405; DOI:10.1016/S0021-9673(97)00621-3

2. Roux C, Novotny M, Evans I and Lennard C, Forensic Sci Int., 1999, 101(3), 167176; DOI:10.1016/S0379-0738(99)00021-3

3. Vila A, Ferrer N and Garcia J F, Anal Chim Acta, 2007, 591(1), 97-105; DOI:10.1016/j.aca.2007.03.060

4. Thanasoulias N C, Parisis N A and Evmiridis N P, Forensic Sci Int.,2003, 138(1-3), 75-84; DOI:10.1016/j.forsciint.2003.08.014

5. Claybourn M and Ansell M, Sci Justice, 2000, 40(4), 261-271; DOI:10.1016/S13550306(00)71996-4

6. White P C, Sci Justice, 2003, 43(3), 149-152; DOI:10.1016/S1355-0306(03)71762-6

7. Lewis J A, J Forensic Sci., 1996, 41(5), 874-877; DOI:10.1520/JFS14015J

8. American Society for Testing Materials, E 1789-96 Standard guide for writing ink identification, Annual Book of ASTM Standards, ASTM International, West Conshohocken, PA, 2000, 14(02), 740-745.

9. Rohde E, Vogt C and Heineman W R, Electrophoresis, 1998, 19(1), 31-41; DOI:10.1002/elps.1150190108

10. Samanidou V F, Nikolaidou K I and Papadoyannis I N, J Liq Chromatogr Related Technol., 2004, 27(2), 215-235; DOI:10.1081/JLC-120027097

11. Zlotnick J A and Smith F P, J Chromatogr B, 1999, 733(1-2), 265-272; DOI:10.1016/S0378-4347(99)00312-6 
12. Tsutsumi K and Ohga K, Anal Sci., 1998, 14(2), 269-274;

DOI:10.2116/analsci.14.269

13. Palus J Z and Kunicki M, J Forensic Sci., 2006, 158(2-3), 164-172; DOI:10.1016/j.forsciint.2005.04.044

14. Weyermann C, Kirsch D, Vera C C and Spengler B, J Forensic Sci., 2007, 168(2-3), 119-127; DOI:10.1016/j.forsciint.2006.06.076

15. Ikeda M and Uchihara H, Polyfile, 1992, 29, 32 . 